\title{
Transient 3D Numerical Simulation of Horizontal Earth Water Heat Exchanger (EWHE)
}

\author{
Hanin Atwany ${ }^{1}$, Mohammad O. Hamdan ${ }^{*},{ }^{1}$, Bassam A. Abu-Nabah', Mousa Attom², Abdul Hai Alami ${ }^{3}$ \\ ${ }^{1}$ Department of Mechanical Engineering, American University of Sharjah \\ Sharjah, United Arab Emirates \\ g00077160@aus.edu; mhamdan@aus.edu; babunabah@aus.edu \\ 2 Department of Civil Engineering, American University of Sharjah \\ Sharjah, United Arab Emirates \\ mattom@aus.edu \\ ${ }^{1}$ Department of Sustainable Renewable Energy Engineering, University of Sharjah \\ Sharjah, United Arab Emirates \\ aalalami@sharjah.ac.ae
}

\begin{abstract}
In this paper, the thermal performance of a horizontal earth tube heat exchanger is investigated. A three-dimensional model has been created using ANSYS Fluent to study the performance of a ground horizontal earth water heat exchanger (EWHE). The effect of inlet water temperature, water velocity, soil thermal conductivity and ground surface temperature on the rate of heat transfer has been analyzed. The results have indicated a direct relation between soil thermal conductivity and the rate of heat transfer. On the other hand, an inverse relation has been observed between ground surface temperature and the rate of heat exchanged. The transient model shows that interim operation of EWHE is needed since ground becomes saturated with thermal energy.
\end{abstract}

Keywords: Earth water heat exchanger; shallow ground thermal energy; ground heat capacity; Soil thermal conductivity.

\section{Introduction}

The demand for energy is growing rapidly due to population growth and human growing needs. One of these needs is providing air-conditioning to assure human comfort. In the GCC region, the cooling needs consume around $70 \%$ of the overall energy produced during summer peak time. To reduce such high demands of energy, engineers are trying to use passive geothermal energy as way to reduce such a high demand. Nevertheless, very few studies are available on the use of geothermal in the GCC region which make it difficult for a field engineer to decide on implementing such an approach.

One approach towards the application of geothermal energy, utilizing shallow ground thermal energy, is the use of earth water heat exchanger (EWHE) which uses earth's massive thermal capacitance provides [1, 2]. Geothermal cooling has been investigated in various regions as a method of decreasing the cooling load [3]. As shown in the literature, EWHE can reduce the energy peak demand and cut fossil fuel consumption, which reduces carbon emissions [4].

The performance of EWHE depends on soil thermal properties and EWHE design parameters. As showed in the literature [5, 6], EWHE thermal conductivity can play a major role in sizing EWHE. The thermal conductivity of soil depends on many parameters including water content, soil compaction and chemical composition. The effect of water content and soil compaction have been investigated by Atwany et al. [7] who showed that water content have more significant effect on varying thermal conductivity than compaction level. The effect of soil on the earth heat exchanger depends on the working fluid used in the heat exchanger [8]. T'Joen et al [8] has showed that the soil thermal conductivity has a strong impact on EWHE in comparison to earth air heat exchanger (EAHE).

Since heat transfer in EWHE is considered a transient and non-uniform process, one needs to implement numerical simulations to obtain proper prediction of EWHE operation performance. Congedo and his team [9] have used numerical simulation to study the performance of horizontal ground heat exchangers under different configurations. Congedo et al. [9] has found that ground thermal conductivity had the greatest impact on the rate of heat transfer followed by the fluid velocity. The effect of EWHE configuration has been numerically examined by Bezyan et al. [10] who has reported that the best performing configuration is the spiral-shaped in serial connection. 
In this paper, a three-dimensional transient numerical simulation is used to study the performance of EWHE. The EWHE used in this study is modeled as a 300-m length horizontal pipe buried at a 2-m depth underneath the surface using commercial computation tool (ANSYS 19.1). The transient state model is used to evaluate how water-soil temperature changes with time while the steady state model is used to study the effect of different parameters on EWHE performance.

\section{Problem Formulation}

This study employs a three-dimensional transient numerical simulation to examine the performance of EWHE. The simulation is conducted using ANSYS Fluent Release 19.1, which follows a finite volume approach.

\subsection{Problem Setup}

A schematic of the computational domain is shown in Figure 1, which resembles a horizontal pipe buried in shallow underground. The dimensions of the computational domain are shown in Table I. The computational domain consists of a rectangular cuboid $(2 \mathrm{~m} \times 4 \mathrm{~m} \times 300 \mathrm{~m})$ representing the soil and a pipe in the center of the rectangular cuboid with a diameter of $30 \mathrm{~mm}$ and length of $300 \mathrm{~m}$.

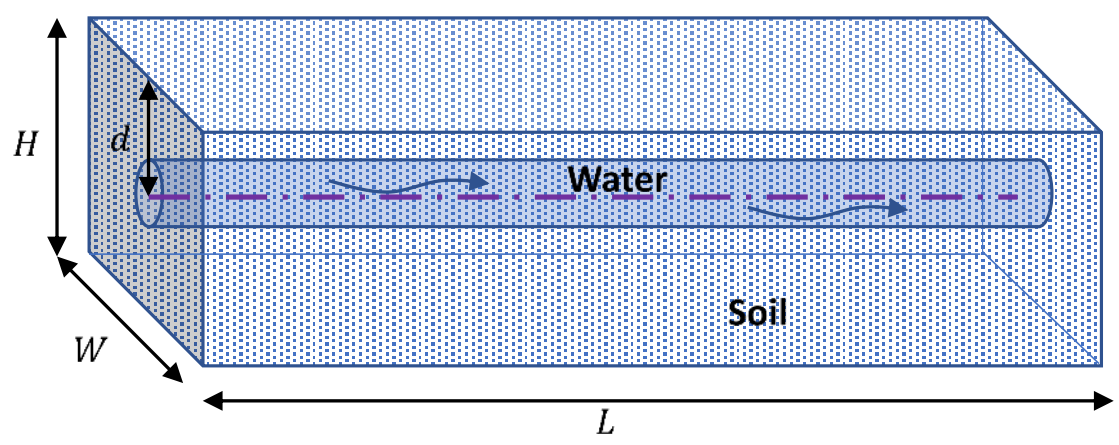

Fig. 1: A three-dimensional schematic of the computational domain (not to scale).

Table 1: Dimension of computational domain.

\begin{tabular}{lcc}
\hline \hline Parameters & Unit & Value \\
\hline Pipe diameter (D) of EWHE & $\mathrm{m}$ & 0.03 \\
Pipe length (L) of EWHE & $\mathrm{m}$ & 300 \\
Pipe buried depth (d) & $\mathrm{m}$ & 2.0 \\
Rectangular cuboid length (L) & $\mathrm{m}$ & 300 \\
Rectangular cuboid width (W) & $\mathrm{m}$ & 2.5 \\
Rectangular cuboid depth (H) & $\mathrm{m}$ & 4.0 \\
\hline \hline
\end{tabular}

The temperature of top and bottom surface temperatures are obtained using Kasuda's model [11]. All other walls are assumed insulated since they are far enough from the pipe. The boundary condition is summarized in Table II. The main numerical simulation is conducted with a water inlet velocity, upper surface temperature and inlet temperature as shown in Table II. The pipe outlet condition is set at a constant outlet pressure and the boundary conditions for the wall separating the water domain and the sand domain are set as coupled walls. This will solve the Navier-Stokes 
equations in the fluid domain and the heat conduction equations in the solid domain (known as conjugate heat transfer).

Table 2: Boundary conditions.

\begin{tabular}{lcc}
\hline \hline Parameter & Units & Value \\
\hline Upper surface temperature & $K$ & 318 \\
Lower surface temperature & $K$ & 303 \\
Inlet water temperature & $K$ & 340 and \\
Inlet water velocity & $\mathrm{m} / \mathrm{s}$ & 0.2123 \\
Outlet water pressure & $\mathrm{kPa}$ & 0 \\
\hline \hline
\end{tabular}

The properties of soil domain and water domain has been set as shown in Table III. These properties are set as homogenous and maintained constant throughout the simulation.

Table 3: Material properties.

\begin{tabular}{lccc}
\hline \hline Property & Units & Water & Sand \\
\hline Heat capacity $\left(C_{p}\right)$ & $\mathrm{J} / \mathrm{kg} \cdot \mathrm{K}$ & 4,183 & 856 \\
Density $(\rho)$ & $\mathrm{kg} / \mathrm{m}^{3}$ & 998.2 & 1,400 \\
Thermal conductivity $(k)$ & $\mathrm{W} / \mathrm{m} \cdot \mathrm{K}$ & 0.6 & 1.4 \\
Dynamic viscosity $(\mu)$ & $\mathrm{kg} /(\mathrm{m} \cdot \mathrm{s})$ & 0.001 & -- \\
\hline \hline
\end{tabular}

\subsection{Numerical Analysis}

The ANSYS Fluent software makes use of the conservation laws for mass, momentum and energy which can be written as follow:

$$
\begin{gathered}
\frac{\partial \bar{u}_{i}}{\partial x_{i}}=0 \\
\frac{\partial \bar{u}_{i}}{\partial t}+\frac{\partial}{\partial x_{j}}\left(\bar{u}_{i} \bar{u}_{j}\right)=-\frac{1}{\rho} \frac{\partial \bar{p}}{\partial x_{i}}+v \frac{\partial^{2} \bar{u}_{i}}{\partial x_{j} \partial x_{j}}-\frac{\partial}{\partial x_{j}}\left(\overline{u_{\imath}^{\prime} u_{\jmath}^{\prime}}\right) \\
\frac{\partial T}{\partial t}+\frac{\partial}{\partial x_{i}}\left(T \bar{u}_{i}\right)=v \frac{\partial^{2} T}{\partial x_{i} \partial x_{i}}-\frac{\partial}{\partial x_{i}}\left(\overline{T^{\prime} u_{\imath}^{\prime}}\right)
\end{gathered}
$$

where $\rho, v, p$ and $\mu$ refer to density, velocity vector, pressure and dynamics viscosity, respectively. $T, c_{p}$ and $k$ refer to temperature, heat capacity and thermal conductivity, respectively.

The flow is assumed to be turbulent and incompressible flow while the heat transfer is considered as transient conjugate heat transfer problem where heat transfers from water to the ground. For high Reynolds numbers and based on literature for similar case [12], the realizable $k-\varepsilon$ model with enhanced wall treatment and thermal effects function has been adopted. The $k-\varepsilon$ model is a two-equation model incorporating the turbulence kinetic energy and the turbulence dissipation rate as shown in equations (4) and (5), respectively [13]. 


$$
\begin{gathered}
\frac{\partial k}{\partial t}+\bar{u}_{j} \frac{\partial k}{\partial x_{j}}=\frac{\partial}{\partial x_{j}}\left[\frac{\left(v+v_{t}\right)}{\sigma_{k}} \frac{\partial k}{\partial x_{j}}\right]-\varepsilon+\tau_{i j} \frac{\partial \bar{u}_{\imath}}{\partial x_{j}} \\
\frac{\partial \varepsilon}{\partial t}+\bar{u}_{j} \frac{\partial \varepsilon}{\partial x_{j}}=\frac{\partial}{\partial x_{j}}\left[\frac{\left(v+v_{t}\right)}{\sigma_{\varepsilon}} \frac{\partial \varepsilon}{\partial x_{j}}\right]+C_{\varepsilon 1} \frac{\varepsilon}{k} \tau_{i j} \frac{\partial \bar{u}_{l}}{\partial x_{j}}-C_{\varepsilon 2} \frac{\varepsilon^{2}}{k}
\end{gathered}
$$

where $\tau_{i j}=\overline{u_{l}^{\prime} u_{\jmath}^{\prime}}, v_{t}=C_{\mu} \frac{k^{2}}{\varepsilon}, \sigma_{k}$ and $\sigma_{\varepsilon}$ are the Prandtl number for $k$ and $\varepsilon$, respectively. This model produces accurate results when studying turbulent shear flows but is inadequate in the presence of rotation or skewing. However, the modified model, realizable $k-\varepsilon$ model is considered to produce accurate results when predicting the flow in a wall-bounded and internal channels as $C_{\mu}$ is no longer constant but is computed using an eddy-viscosity equation. The constants of the realizable $k-\varepsilon$ model are $C_{\varepsilon 1}=1.44, C_{\varepsilon 2}=1.9, \sigma_{k}=1.0$ and $\sigma_{\varepsilon}=1.2$.

The current transient conjugate heat transfer problem has been solved using Semi-Implicit Method for Pressure Linked Equations (SIMPLE) algorithm. The default discretization has been adopted which implements a second-order upwind discretization for momentum and energy equations and first-order upwind discretization for Turbulence model equations.

A three-dimensional mesh has been used in this study as shown in Figure 2, where the mesh has been refined in the flow region as the highest gradients are expected there and coarser in the soil region as convection is of a greater importance in comparison to conduction in this problem. Heat transfer in solids is due to conduction and the use of big element sizes is acceptable since the main object of these domains is to guarantee proper heat transfer to the pipe. The mesh used for the pipe is relatively fine to assure capturing the forced convection heat transfer at the wall.

To check for mesh independence, different meshes are tested. The results for three different meshes are shown in Figure 3 which shows how temperature varies with pipe length. Figure 3 reports the results for three mesh sizes, mainly, mesh \#1 with 9,205,466 nodes, mesh \#2 with 7,987,446 nodes and mesh \#3 with 5,643,128 nodes. The results in Figure 3 show that mesh \#2 produces comparable results as mesh \#1 but with less nodes and less processing time, hence, mesh \#2 has been selected.

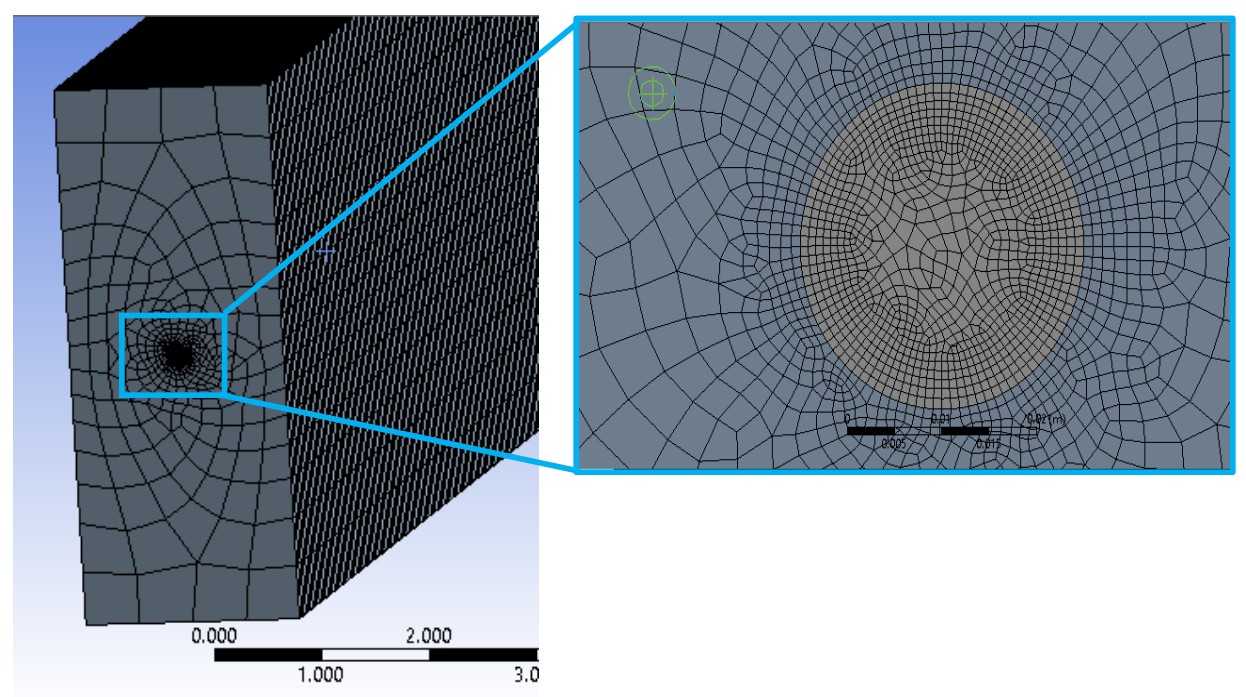

Fig. 2: Mesh used in the simulation with a zoomed-in view to the side of the soil rectangular cuboid to show the pipe cross section. 


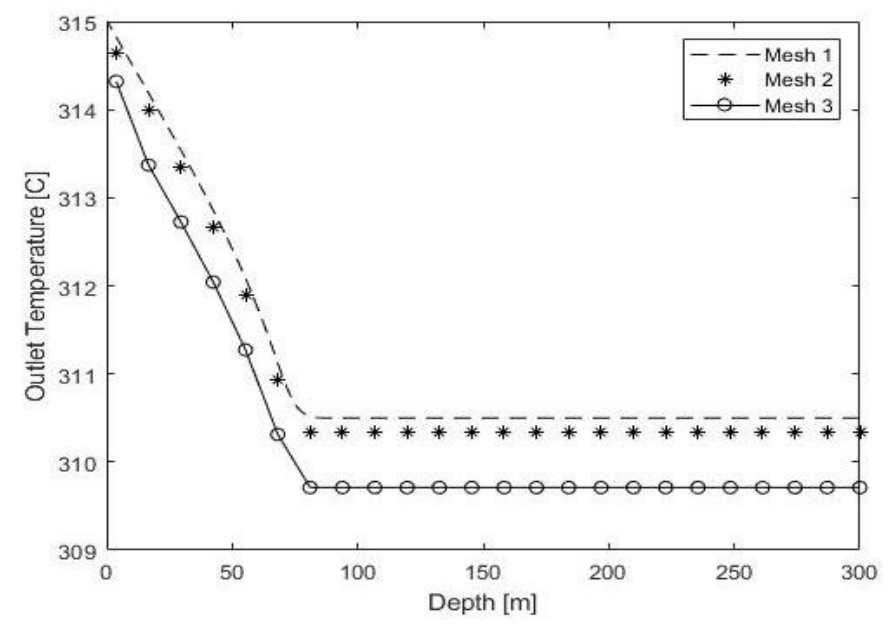

Fig. 3: Mesh independence test (9,205,466 nodes for mesh \#1, 7,987,446 nodes for mesh \#2 and 5,643,128 nodes for mesh \#3).

\section{Results and discussion}

\subsection{Transient 3D Numerical Simulation}

The four lines plotted in Figure 4 represent the temperature of water along the pipe at different times, namely 300 , 800,1000 , and $1500 \mathrm{~s}$. Figure 4 shows that water temperature decreases with pipe length since longer pipes means bigger heat transfer area, hence, lower water temperature is expected. As shown in Figure 4, the ground temperature is rising with time causing higher water to exist in the pipe. This means as time passes, the ground temperature increases which reduces the heat transfer between the water and the ground.

Figure 5 is similar to Figure 4, however in this case water inlet temperature was reduced to $315 \mathrm{~K}$ while ground temperature condition is kept the same as mentioned before. Similar trends are observed in this figure as the one seen in Figure 4, however the temperature gradient with pipe length is less sever since inlet temperature is lower than the case plotted in Figure 4. The temperature gradient in Figure 5 over 300 meter and 2000 seconds is less than $5{ }^{\circ} \mathrm{C}$. In Figure 4 , the temperature gradient over 100 meter and 1500 seconds is around $20{ }^{\circ} \mathrm{C}$. Less temperature gradient means less heat transfer occurs between water and the ground which is mainly driven by lower water inlet temperature. Also, since less heat transfers to the ground, the ground temperature will take longer before it raises substantially. This allows the ground to dissipate heat over longer period.

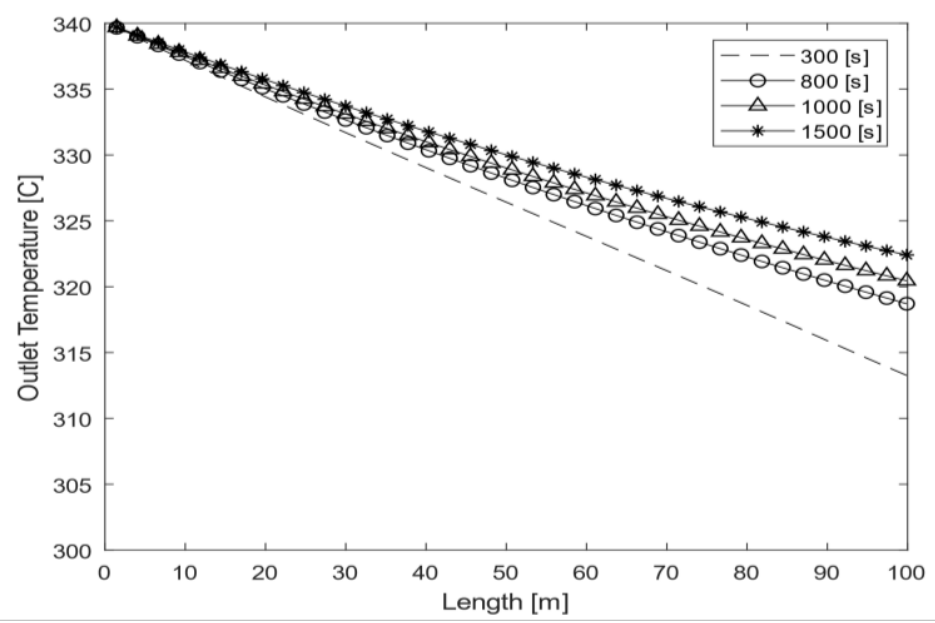

Fig. 4: Outlet temperature over pipe length at various running times with inlet temperature of $340 \mathrm{~K}$ and inlet velocity of $0.2123 \mathrm{~m} / \mathrm{s}$. 


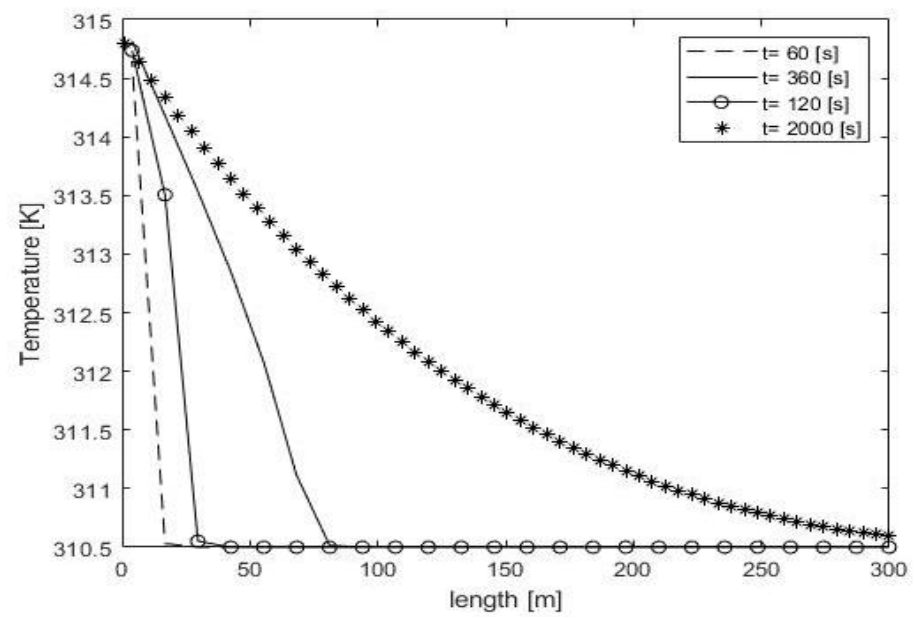

Fig. 5: Outlet temperature over pipe length at various running times with inlet temperature of $315 \mathrm{~K}$ and inlet velocity of $0.2123 \mathrm{~m} / \mathrm{s}$.

\subsection{Steady State 3D Numerical Simulation}

To properly understand the effect of soil thermal conductivity, water inlet temperature, fluid velocity and ground surface temperature, a steady state numerical simulation is conducted using the mesh described in earlier section.

In Figure 6, the effect of soil thermal conductivity on water outlet temperature is presented. It is observed that as soil thermal conductivity increases, the amount of heat transfer from the pipe to the soil increases, hence water outlet temperature decreases. The increase in rate of heat exchange is proportional to the increase in soil thermal conductivity. This is deduced from the decreasing outlet temperature at higher soil thermal conductivities. Thus, it is critical to test the soil thermal conductivity prior to the installation of a ground heat exchanger since this will dramatically dictate the size and length of the EWHE. A soil thermal conductivity of $3 \mathrm{~W} / \mathrm{m}$. K resulted in a temperature drop greater than $10^{\circ} \mathrm{C}$. In general, sizing the EWHE will depend on the application requirements.

Figure 7 shows the effect of fluid velocity on water outlet temperature. It demonstrates that increasing the flow rate increases the water outlet temperature, which is not desirable. Higher flow rates mean more heat transfer however this happens at higher temperature. A higher velocity results in a greater mass flow rate. An inverse relationship has been observed between the mass flow rate and $\Delta T$ for a constant rate of heat transfer. It is expected that as the velocity increases, the Reynolds number increases but the time of contact between the fluid and the ground is reduced. For cooling applications, a higher $\Delta T$ is desired. Thus, a compromise between flow rate and residence time is needed to optimize the amount of heat transfer.

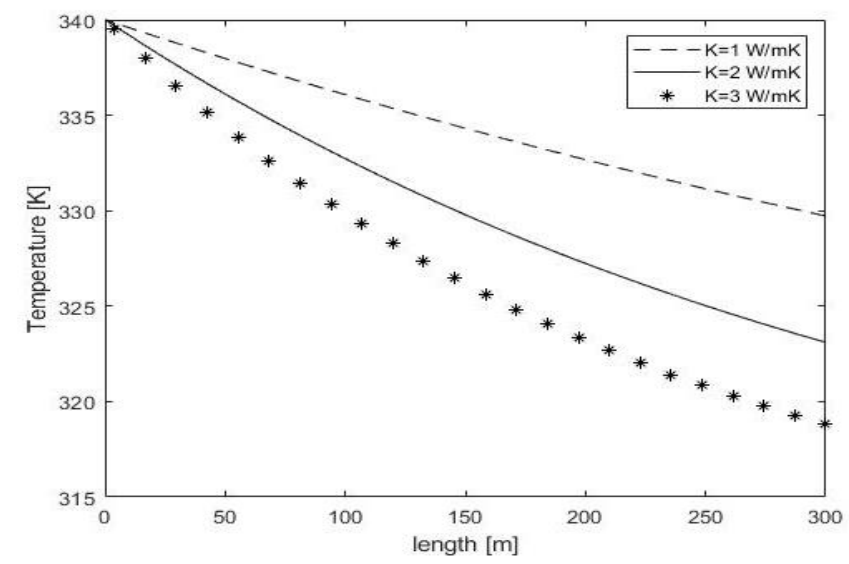

Fig. 6: Effect of soil thermal conductivity on water outlet temperature. 


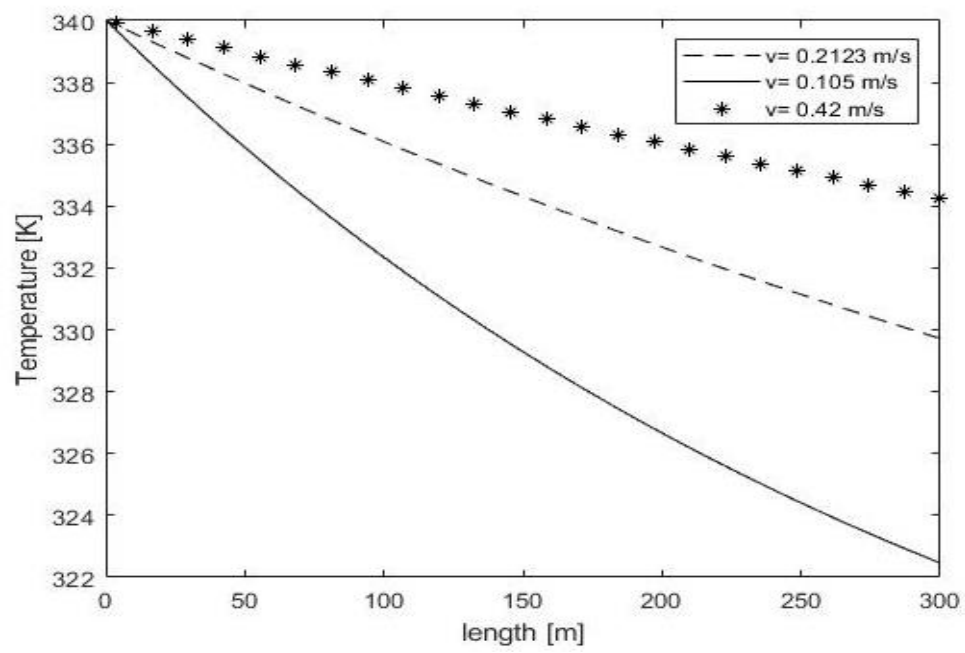

Fig. 7: Effect of fluid velocity on water outlet temperature.

It is established that a high temperature difference between the inlet fluid and the outlet fluid indicates an enhanced EWHE performance [14]. The effect of inlet temperature is shown in Figure 8, where inlet temperature varies between 330 $\mathrm{K}$ and $350 \mathrm{~K}$. The slope at an inlet temperature of $350 \mathrm{~K}$ is steeper compared to the other cases which indicates a greater heat exchange rate. Thus, inlet temperature is a significant parameter that has a major impact on the outcome of the heat exchanger [15]. The inlet temperature to the system will depend on the cooling load where a greater load results in a higher temperature.

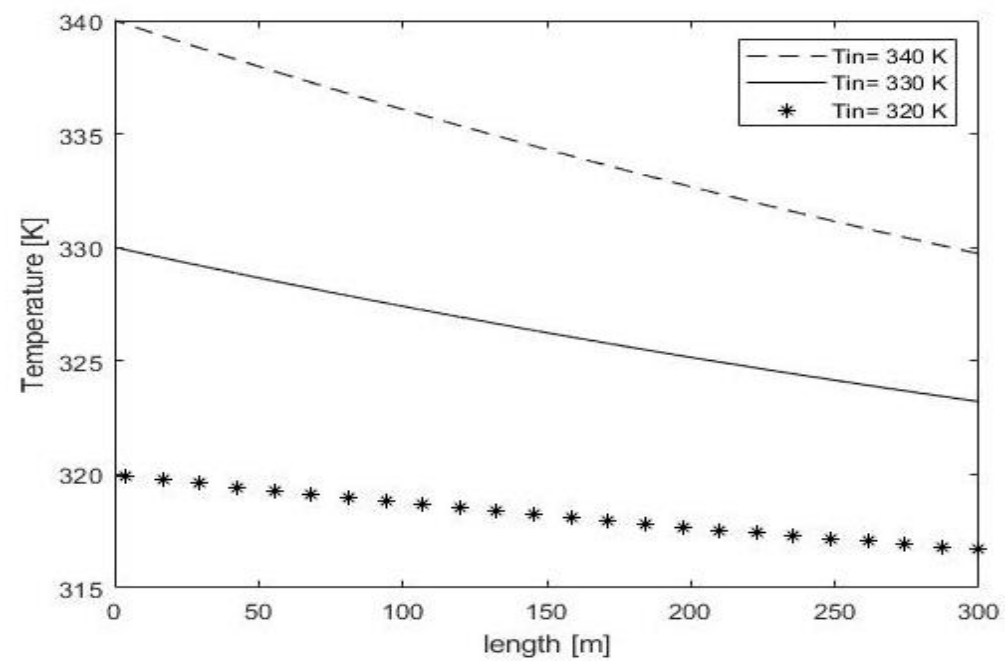

Fig. 8: Effect of fluid inlet temperature on water outlet temperature.

\section{Conclusion}

This work studies the performance of a horizontal EWHE. The transient numerical simulation showed that ground temperature increases when hot fluid is passing in the soil. Under the same flow rate, the water inlet temperature can dramatically affect the performance of EWHE. The ground reaches a saturation condition faster with higher inlet temperature. The higher the soil thermal conductivity, the easier for the energy to penetrate the soil. The higher flow rate leads to a higher amount of heat to pass to the ground however it increases the outlet water temperature which is not 
desirable. Increasing water inlet temperature assure higher temperature drop across the EWHE which is more desirable. This study emphasis the need of experimental study and feasibility study which currently is being conducted at Sharjah.

\section{Acknowledgment}

The authors would like to acknowledge the American University of Sharjah for the providing support for this research. This work was financially supported by the Research Office at American University of Sharjah under research grant contract number EFRG18-SCR-CEN-35 through EFRG for Smart Cities Research 2018-2020.

\section{References}

[1] J. Egg and B. C. Howard, Geothermal HVAC: McGraw Hill Professional, 2010.

[2] H. Atwany, M. O. Hamdan, B. A. Abu-Nabah, A. H. Alami, and M. Attom, "Experimental evaluation of ground heat exchanger in UAE," Renewable Energy, 2020.

[3] M.-J. Kim, S.-R. Lee, S. Yoon, and G.-H. Go, "Thermal performance evaluation and parametric study of a horizontal ground heat exchanger," Geothermics, vol. 60, pp. 134-143, 2016.

[4] G. Hellström, B. Sanner, M. Klugescheid, T. Gonka, and S. Mårtensson, "Experiences with the borehole heat exchanger software EED," Proc. Megastock, vol. 97, pp. 247-252, 1997.

[5] M. O. Hamdan, "Tapping to geothermal energy through a high performance earth-to-water heat exchanger design," in 2018 5th International Conference on Renewable Energy: Generation and Applications (ICREGA), 2018, pp. 207-210.

[6] H. Atwany, M. Hamdan, M. Attom, B. Abu-Nabah, and A. Alami, Performance of earth-water heat exchanger for cooling applications, 2019.

[7] H. Atwany, M. Attom, M. O. Hamdan, B. A. Abu-Nabah, and A. H. Alami, "Evaluating thermal conductivity of desert sand under different initial physical properties," 2018.

[8] C. T'Joen, L. Liu, and M. D. Paepe, "Comparison of Earth-Air and Earth-Water Ground Tube Heat Exchangers for Residentialal Application," 2012.

[9] P. Congedo, G. Colangelo, and G. Starace, "CFD simulations of horizontal ground heat exchangers: A comparison among different configurations," Applied Thermal Engineering, vol. 33, pp. 24-32, 2012.

[10] B. Bezyan, S. Porkhial, and A. A. Mehrizi, "3-D simulation of heat transfer rate in geothermal pilefoundation heat exchangers with spiral pipe configuration," Applied Thermal Engineering, vol. 87, pp. 655-668, 2015.

[11] T. Kusuda and P. R. Achenbach, "Earth temperature and thermal diffusivity at selected stations in the United States," National Bureau of Standards Gaithersburg MD1965.

[12] S. Selamat, A. Miyara, and K. Kariya, "Numerical study of horizontal ground heat exchangers for design optimization," Renewable energy, vol. 95, pp. 561-573, 2016.

[13] C. Argyropoulos and N. Markatos, "Recent advances on the numerical modelling of turbulent flows," Applied Mathematical Modelling, vol. 39, pp. 693-732, 2015.

[14] M. Ali, K. Kariya, and A. Miyara, "Performance analysis of slinky horizontal ground heat exchangers for a ground source heat pump system," Resources, vol. 6, p. 56, 2017.

[15] R. Karabacak, Ş. G. Acar, H. Kumsar, A. Gökgöz, M. Kaya, and Y. Tülek, "Experimental investigation of the cooling performance of a ground source heat pump system in Denizli, Turkey," International journal of refrigeration, vol. 34, pp. 454-465, 2011. 